\title{
Correction
}

\section{Correction: A Role for Homeostatic Drive in the Perpetuation of Complex Chronic Illness: Gulf War Illness and Chronic Fatigue Syndrome}

\section{The PLOS ONE Staff}

An error occurred in Equation 2 causing "..." to be replaced with a double arrow. Please see the corrected Equation 2 here:

$x_{i}(t+1)=\left\{\begin{array}{c}\left(x_{i 1}^{A}(t) \vee x_{i 2}^{A}(t) \ldots x_{i j}^{A}(t)\right) \nabla\left(x_{i 1}^{I}(t) \vee x_{i 2}^{I}(t) \ldots x_{i k}^{I}(t)\right) \\ \left(x_{i 1}^{A}(t) \vee x_{i 2}^{A}(t) \ldots x_{i j}^{A}(t)\right) \\ \neg\left(x_{i 1}^{I}(t) \vee x_{i 2}^{I}(t) \ldots x_{i k}^{I}(t)\right)\end{array}\right.$

\section{Reference}

1. Craddock TJA, Fritsch P, Rice MA Jr, del Rosario RM, Miller DB, et al. (2014) A Role for Homeostatic Drive in the Perpetuation of Complex Chronic Illness: Gulf War Illness and Chronic Fatigue Syndrome. PLoS ONE 9(1): e84839. doi: $10.1371 /$ journal.pone.0084839
Citation: The PLOS ONE Staff (2014) Correction: A Role for Homeostatic Drive in the Perpetuation of Complex Chronic Illness: Gulf War Illness and Chronic Fatigue Syndrome. PLoS ONE 9(4): e94161. doi:10.1371/journal.pone.0094161

Published April 3, 2014

Copyright: () 2014 The PLOS ONE Staff. This is an open-access article distributed under the terms of the Creative Commons Attribution License, which permits unrestricted use, distribution, and reproduction in any medium, provided the original author and source are credited. 